\title{
Compact Wideband Microstrip Patch Antenna for Wireless Communication
}

\author{
Biplab bag ${ }^{\# 1}$, Partha Pratim Sarkar ${ }^{* 2}$ \\ ${ }^{\# 1}$ Assistant Professor, Department of Electronics and Instrumentation Engineering, Murshidabad College of \\ Engineering and Technology, West Bengal, India \\ ${ }^{2}$ Professor, Department of Engineering and Technological Studies, Kalyani University, West Bengal, India \\ ${ }^{1}$ bbagateie@gmail.com \\ ${ }^{3}$ parthabe91@yahoo.co.in
}

\begin{abstract}
In the present paper, a compact single layer wideband microstrip antenna has been proposed. The proposed antenna consists of a $U$-shaped strip inside the rectangular ring and a defected ground plane is on the other side of strip. The antenna has wide impedance bandwidth of 4.66GHz (3.688.34GHz). The measured percentage of bandwidth is $77.5 \%$, centered at $6.01 \mathrm{GHz}$. Different resonant frequencies are collectively merged together resulting in a single wideband operation. The proposed antenna is also compact in size and the overall dimension is $12 \times 16 \times 1.6 \mathrm{~mm}^{3}$. The proposed antenna covers the performance of WLAN, WiMAX and ITU operations which is much useful in modern wireless communication system. The detail performances of the proposed are demonstrated along with measured and simulated results.
\end{abstract}

Keyword-Compact, Single layer, Wideband, U-shaped strip, Wireless communication

\section{INTRODUCTION}

The rapid development of wireless communication system such as mobile phone, tablets and other portable electronics devices demands dual or multiband operation, wide bandwidth, compact size and high speed data connectivity. All these criteria may be fulfilled by microstrip patch antenna. Enhancement of the bandwidth is one of the challenging tasks for microstrip antenna because it has narrow bandwidth [1] and the researchers try to design an antenna to improve the bandwidth with several structural configurations without increasing the volume of the structure. Numerous articles have been published in the field of antenna of dual and multiband operations with wide bandwidth characteristics. A modified triangular split ring resonator for WLAN/WiMAX/ITU applications [2], desktop shaped [3], multiband bow-tie dipole slot antenna [4], modified rhombus slot antenna [5], rotated U-shaped conductor-backed plane monopole antenna [6], inverted A-shaped patch antenna [7], defected ground structure [8], annular rings patch antenna [9], complementary slots on the ground plane [10], concentric split ring structure [11] have already been reported in published papers.

Compared to previous works, the proposed antenna has couple of advantages that it is more compact in size and has wide impedance bandwidth.

In this paper, a novel compact wide band microstrip feed antenna is proposed to be used in wireless communication, which may cover the WLAN, WiMAX along with ITU band applications. The $-10 \mathrm{~dB}$ impedance bandwidth is obtained as $4.66 \mathrm{GHz}(3.68-8.34 \mathrm{GHz})$ and the percentage of size reduction is $50.2 \%$. The antenna has three resonant frequencies at $5.2 \mathrm{GHz}, 6.54 \mathrm{GHz}$ and $7.9 \mathrm{GHz}$. The proposed antenna consists of a rectangular ring with a U-shape strip inside the ring. The rectangular ring and U-shaped strip is printed on the one side of FR4 epoxy dielectric substrate and a defected ground plane on the other side of the substrate. The designed antenna is fabricated and its measured results are compared with the simulation results obtained from simulation software HFSS. The measured results are comparatively in good agreement with impedance bandwidth, gain and omni-directional radiation pattern. The details of the proposed antenna design and results are described in the following sections.

\section{ANTENNA DESIGN}

Figure 1 shows the geometry of proposed wideband antenna with rectangular ring and U-shaped strip for wireless communication. A $50 \mathrm{ohm}$ microstrip feed line of width $\mathrm{W}_{\mathrm{f}}$ and length $\mathrm{L}_{\mathrm{f}}$ is printed on the top of the FR4 epoxy substrate with relative permittivity $\left(\mathcal{E}_{\mathrm{r}}\right) 4.4$ and loss tangent 0.025 . The thickness of the substrate is $1.6 \mathrm{~mm}$ and a partial ground plane on the other side of the substrate. The overall size of the proposed antenna is taken as $12 \times 16 \times 1.6 \mathrm{~mm}^{3}$. The length of the U-shape strip length is taken about quarter of the effective wavelength $\left(\lambda_{\text {eff }}\right)$, calculated for desired resonant frequency. 


$$
\begin{aligned}
& W=\frac{C}{2 f_{r}} \sqrt{\frac{2}{\varepsilon_{r}+1}} \\
& L=\frac{1}{2 f_{r} \sqrt{\varepsilon_{\text {eff }}} \sqrt{\mu_{0} \varepsilon_{0}}}-2 \Delta L \\
& \lambda_{\text {eff }}=\frac{C}{f_{r} \sqrt{\varepsilon_{\text {eff }}}} \\
& \varepsilon_{\text {eff }}=\frac{\left(\varepsilon_{r}+1\right)}{2}+\frac{\left(\varepsilon_{r}-1\right)}{2}\left[1+\frac{10 h}{W}\right]^{-\frac{1}{2}}
\end{aligned}
$$

The dimensions of the various parameters of the antenna are finalized after large number of simulated results which is done by HFSS v.11 software. The optimum values of parameters are set and that are listed as follows (in mm): $\mathrm{L}_{\mathrm{S}}=30, \mathrm{~W}_{\mathrm{S}}=30, \mathrm{~W}_{\mathrm{P}}=16, \mathrm{~L}_{\mathrm{P}}=12, \mathrm{~W}_{\mathrm{f}}=3.06, \mathrm{~L}_{\mathrm{f}}=7.5, \mathrm{~L}_{\mathrm{g}}=5.5, \mathrm{~L}_{1}=7, \mathrm{~W}_{1}=0.7, \mathrm{~W}_{2}=1.5, \mathrm{~W}_{3}=1.5, \mathrm{~W}_{4}=2.2$, $\mathrm{C}_{1}=1.3, \mathrm{C}_{2}=9.2, \mathrm{p}=2.5, \mathrm{~s}=2$.

The proposed antenna has been designed through three consecutive steps. The design begins with \#Ant.01, which consists of a rectangular patch and a microstrip feed line. The return loss of corresponding design presented in Fig. 2, \#Ant.01 covers the frequency range from $2.4-8.62 \mathrm{GHz}(\mathrm{BW}: 6.22 \mathrm{GHz})$. Then rectangular ring patch has been considered which covers the frequency range from $2.1-6.35 \mathrm{GHz}$ (BW: $4.25 \mathrm{GHz}$ ), resonant in dual mode at $3.0 \mathrm{GHz}$ and $5.36 \mathrm{GHz}$. The corresponding return loss is shown in Fig. 2. Finally a U-shaped strip has been introduced, which is excited at frequencies of $3.24 \mathrm{GHz}, 5.5 \mathrm{GHz}$ and $6.06 \mathrm{GHz}$ with a single band. The \#Ant.03 has impedance bandwidths of $4.41 \mathrm{GHz}(2.1-6.51 \mathrm{GHz})$. By comparing the bandwidth between \#Ant.01 and \#Ant.03, it is clear that \#Ant.01 has slightly larger bandwidth but introducing a U-shaped strip into the \#Ant.03 the effective area of the patch has been reduced by $50.2 \%$.

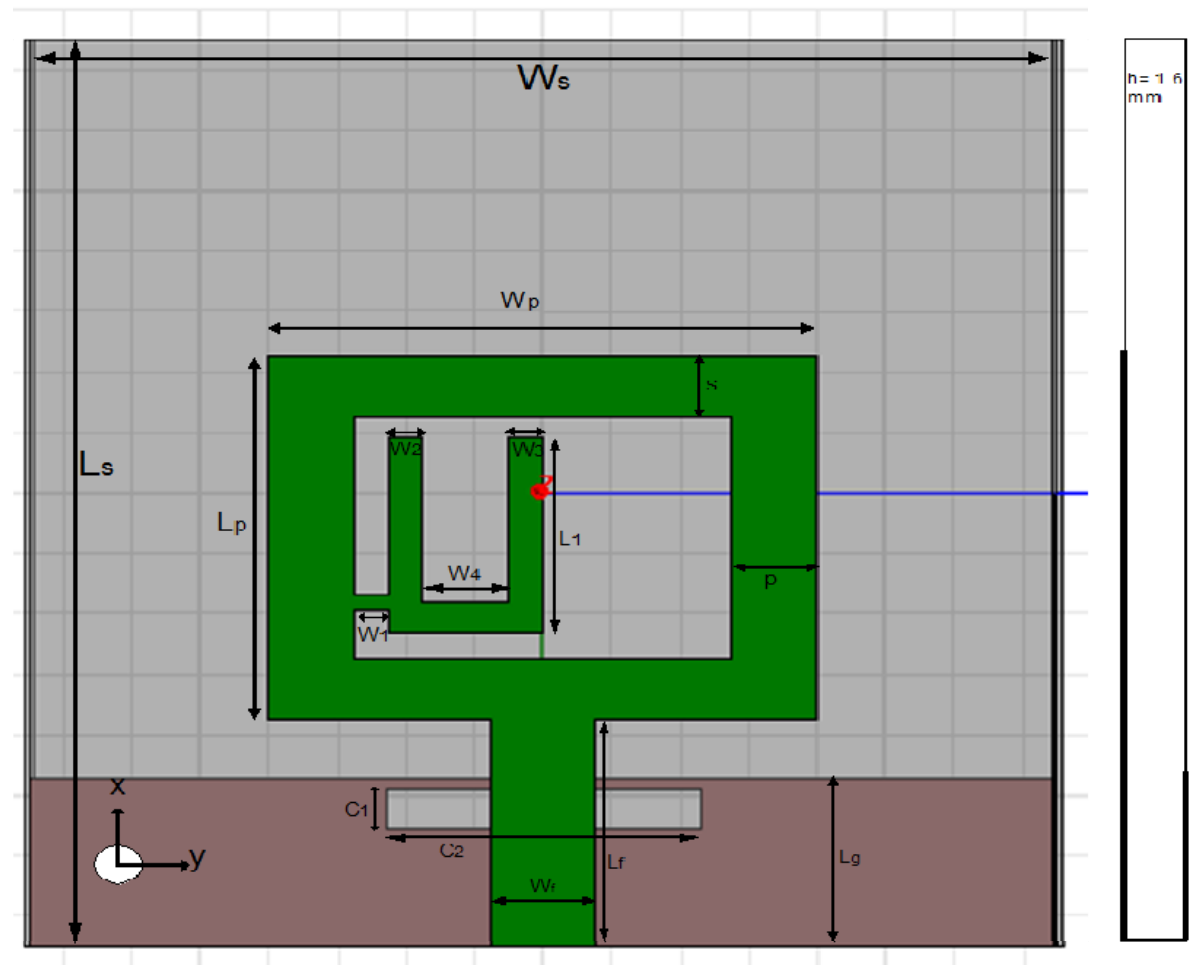

Fig. 1. Geometry of the proposed antenna from patch side 


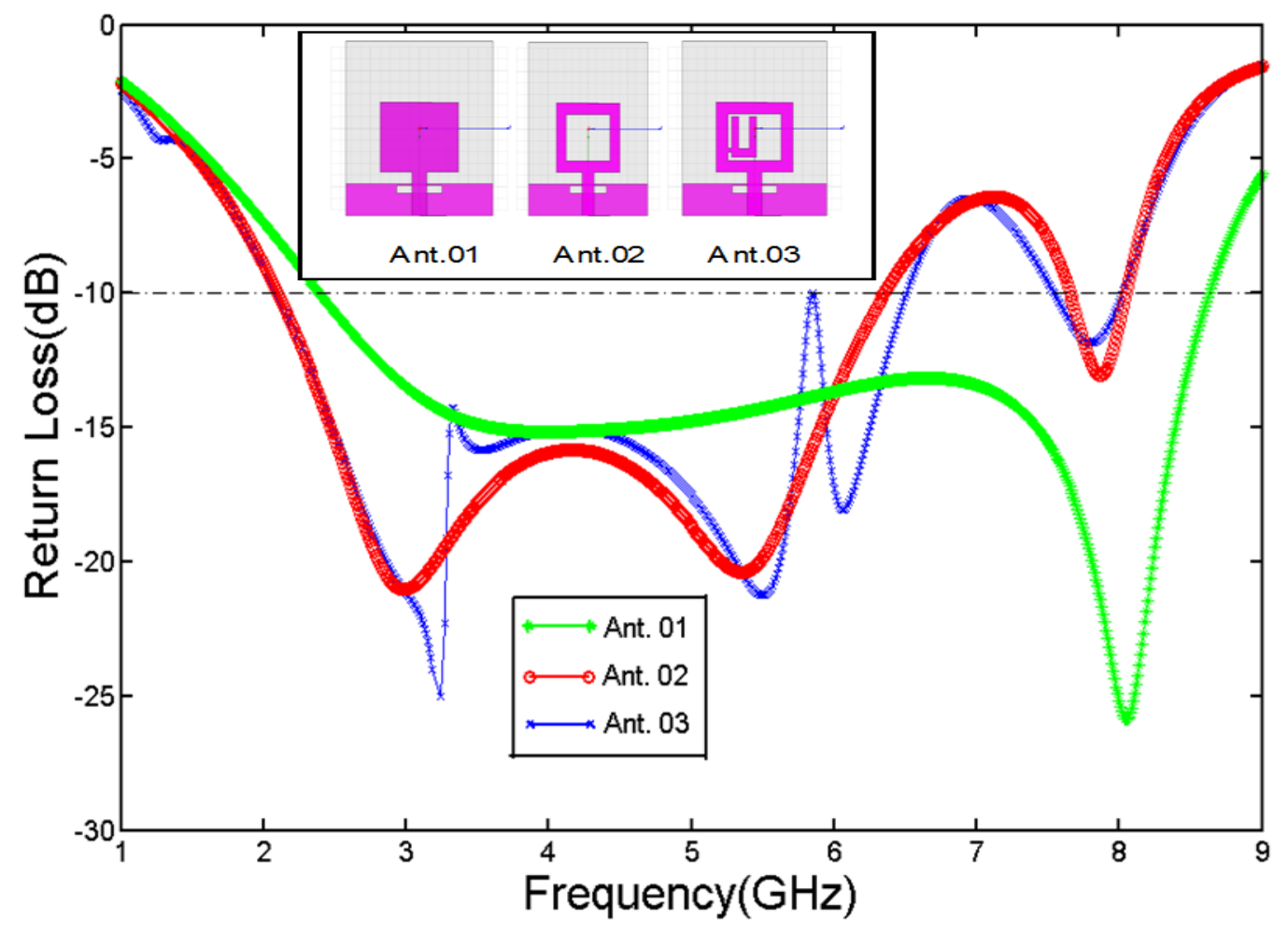

Fig. 2. Simulated return losses of different antenna structure

\section{SIMULATED RESULTS}

The required numerical analysis is carried out and geometrical parameters of proposed antenna are obtained with the help of HFSS v.11 software. The simulated return loss of the proposed antenna is presented in Fig. 3. It can be seen that an acceptable return loss has been obtained from simulation. The simulated results give resonant frequency at $3.24 \mathrm{GHz}$ (with corresponding return loss is $-25 \mathrm{~dB}), 5.5 \mathrm{GHz}(-21.26 \mathrm{~dB})$ and $6.06 \mathrm{GHz}(-$ $18.06 \mathrm{~dB}$ ) with $-10 \mathrm{~dB}$ impedance bandwidth of $4.41 \mathrm{GHz}$.

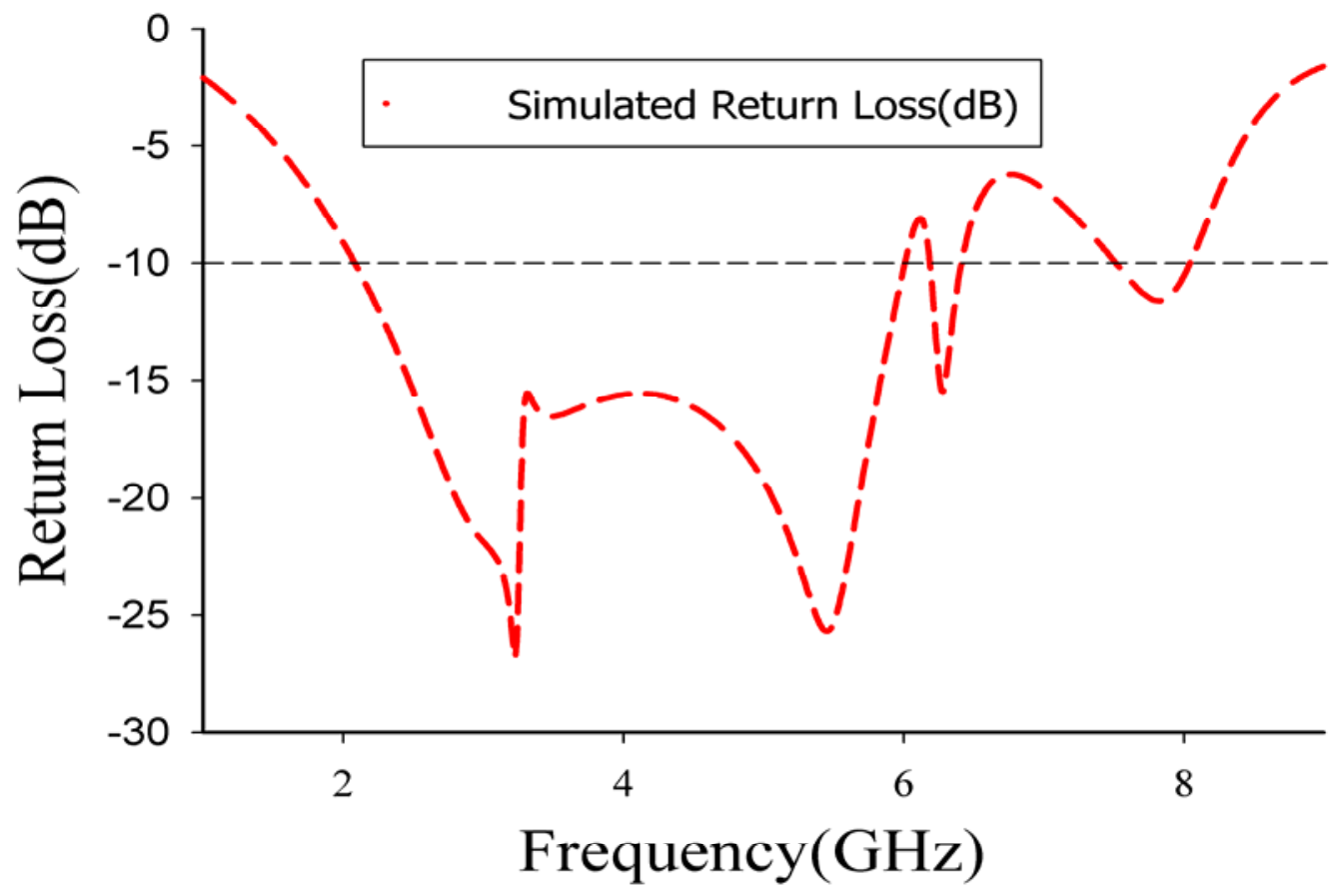

Fig. 3. Simulated return loss $(\mathrm{dB})$ vs. frequency $(\mathrm{GHz})$ 


\section{RESULTS AND DISCUSSION}

In this section, the comparison between simulated and measured return loss, VSWR radiation pattern and gain characteristics are introduced and discussed. The photograph of top view and back view of the fabricated proposed antenna is shown in Fig. 4. The measured data have been obtained using Rohde and Schwarz ZVA 40 and the experiments have been carried out at Kalyani University, India. The comparison of the simulated return loss and measured return loss are shown in Fig. 5. The measured values have been shifted slightly from the simulation due to fabrication tolerance, uncertainty in thickness of substrate and soldering of SMA connector to antenna. Nevertheless, the antenna has achieved wide impedance bandwidth which was main aim of this proposed design. The measured $-10 \mathrm{~dB}$ impedance bandwidth is $4.66 \mathrm{GHz}$ from $3.68 \mathrm{GHz}$ to $8.34 \mathrm{GHz}$. The percentage bandwidth is $77.5 \%$ cantered at $6.01 \mathrm{GHz}$. This bandwidth covers several wireless service applications including WiMAX (3.5/5.5), WLAN (5.2/5.8) and ITU bands. The experimentally measured value of VSWR is compared with that obtained from simulated value which is shown in Fig. 6. The measured VSWR is observed to be almost constant $(<2)$ around the operating band. The measured VSWR at $5.2 \mathrm{GHz}, 6.54 \mathrm{GHz}$ and $7.9 \mathrm{GHz}$ are $1.29,1.21$ and 1.09 , respectively.

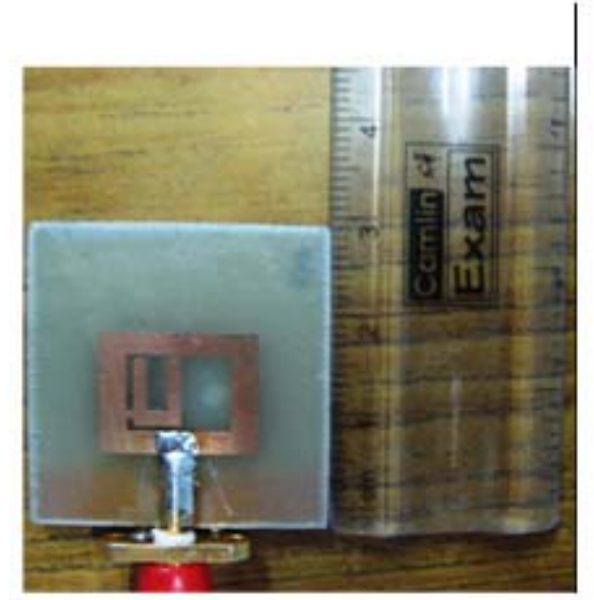

(a)

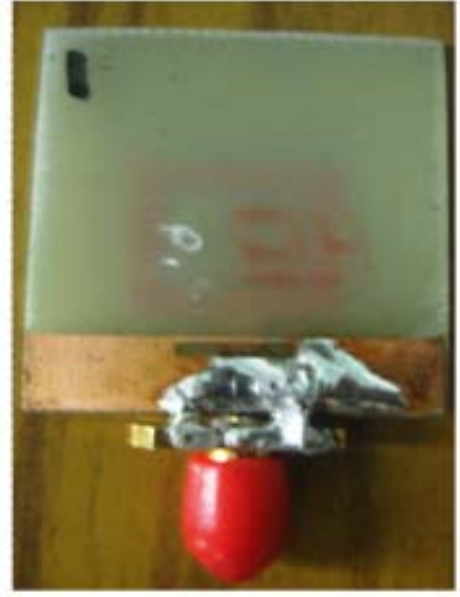

(b)

Fig. 4. Photograph of the proposed antenna (a) top view (b) bottom view

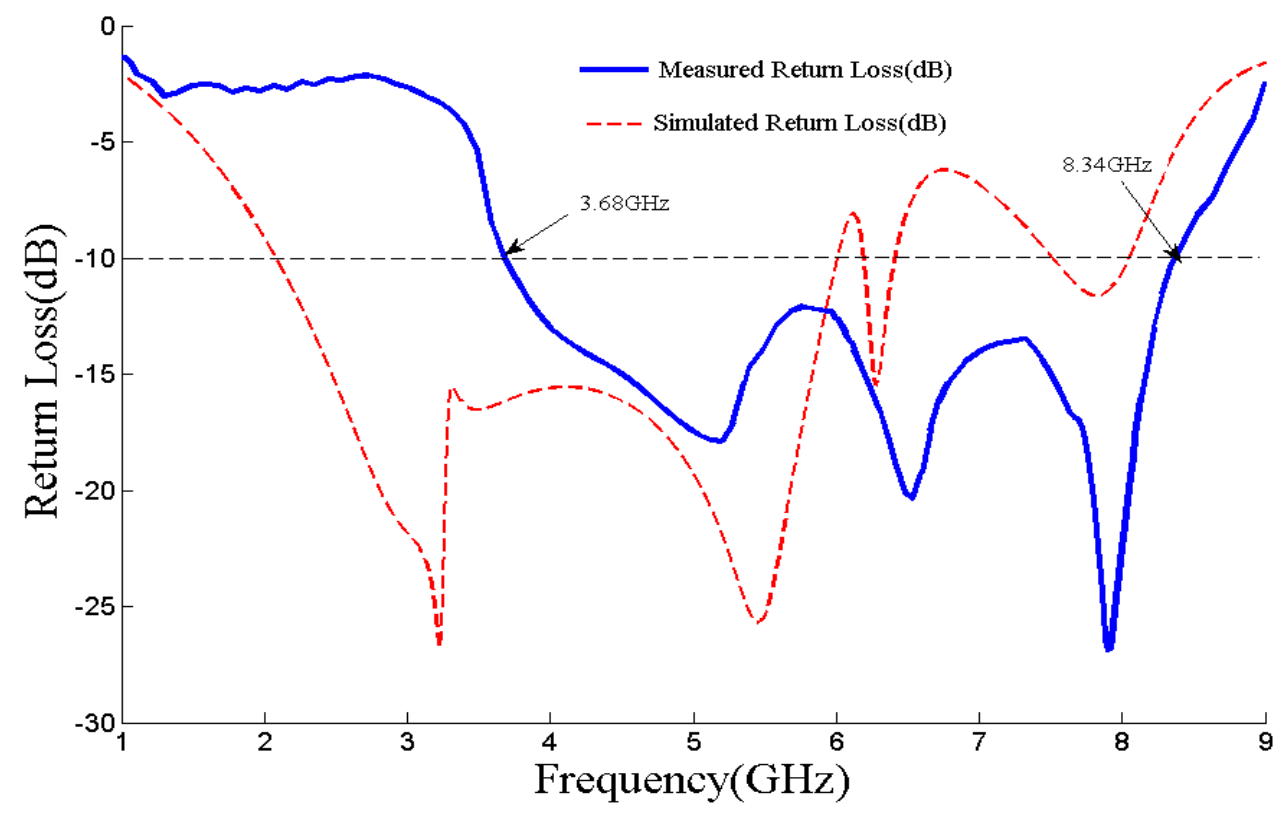

Fig. 5. Comparison of simulated and measured return loss vs. frequency 


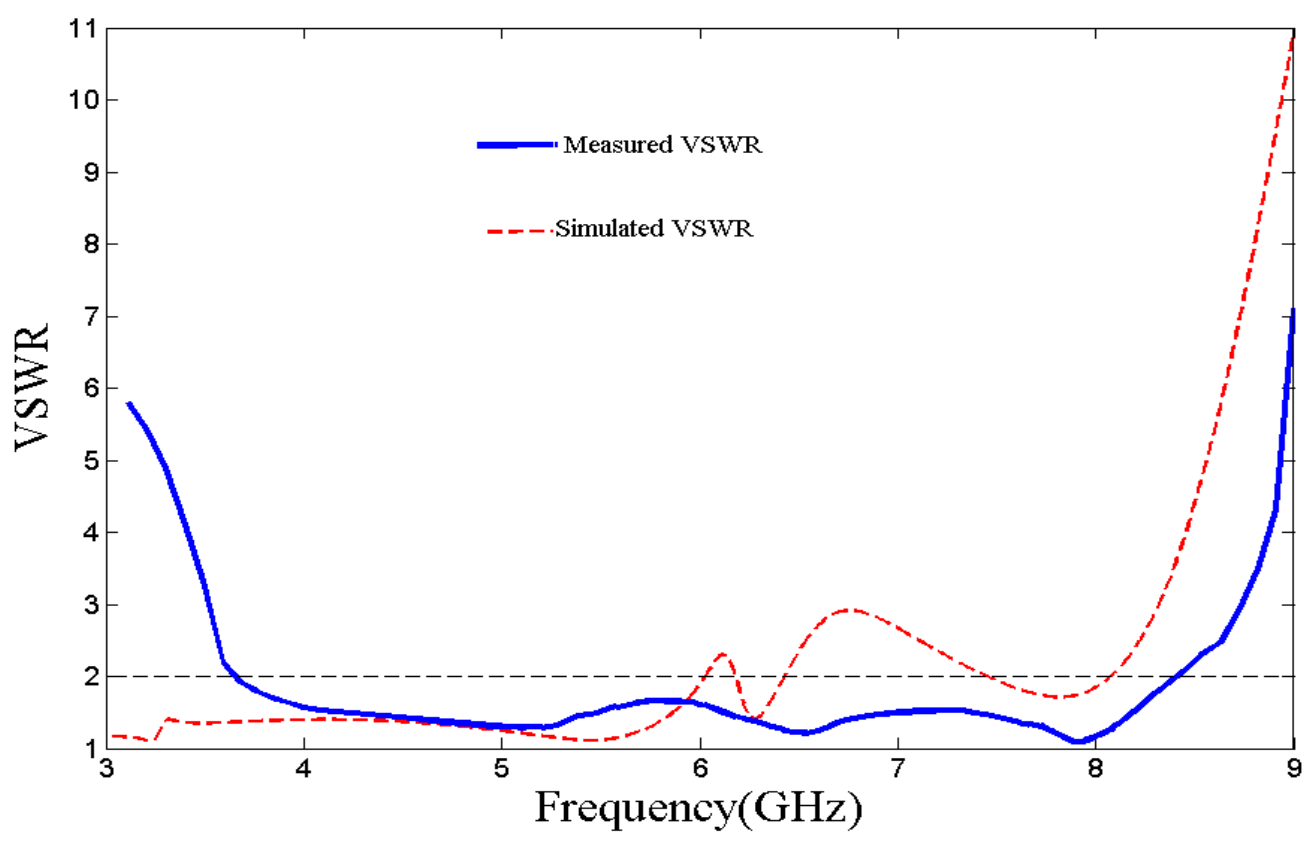

Fig. 6. Measured VSWR of proposed antenna

The Measured values of E-plane and H-plane radiation pattern of the proposed antenna at $5.2 \mathrm{GHz}$ and 6.54GHz are shown in Fig. 7 and Fig. 8, respectively. The E-plane radiation pattern at $5.20 \mathrm{GHz}$ and $6.54 \mathrm{GHz}$ have almost the shape of 8 and the H-plane radiation patterns obtained at $5.20 \mathrm{GHz}$ and $6.54 \mathrm{GHz}$ are found to be omni-directional nature. On the other hand, simulated co-polarization and cross-polarization of E-plane and H-plane radiation patterns obtained at $7.9 \mathrm{GHz}$ is shown in Fig. 9 which to be bit of distorted in nature.

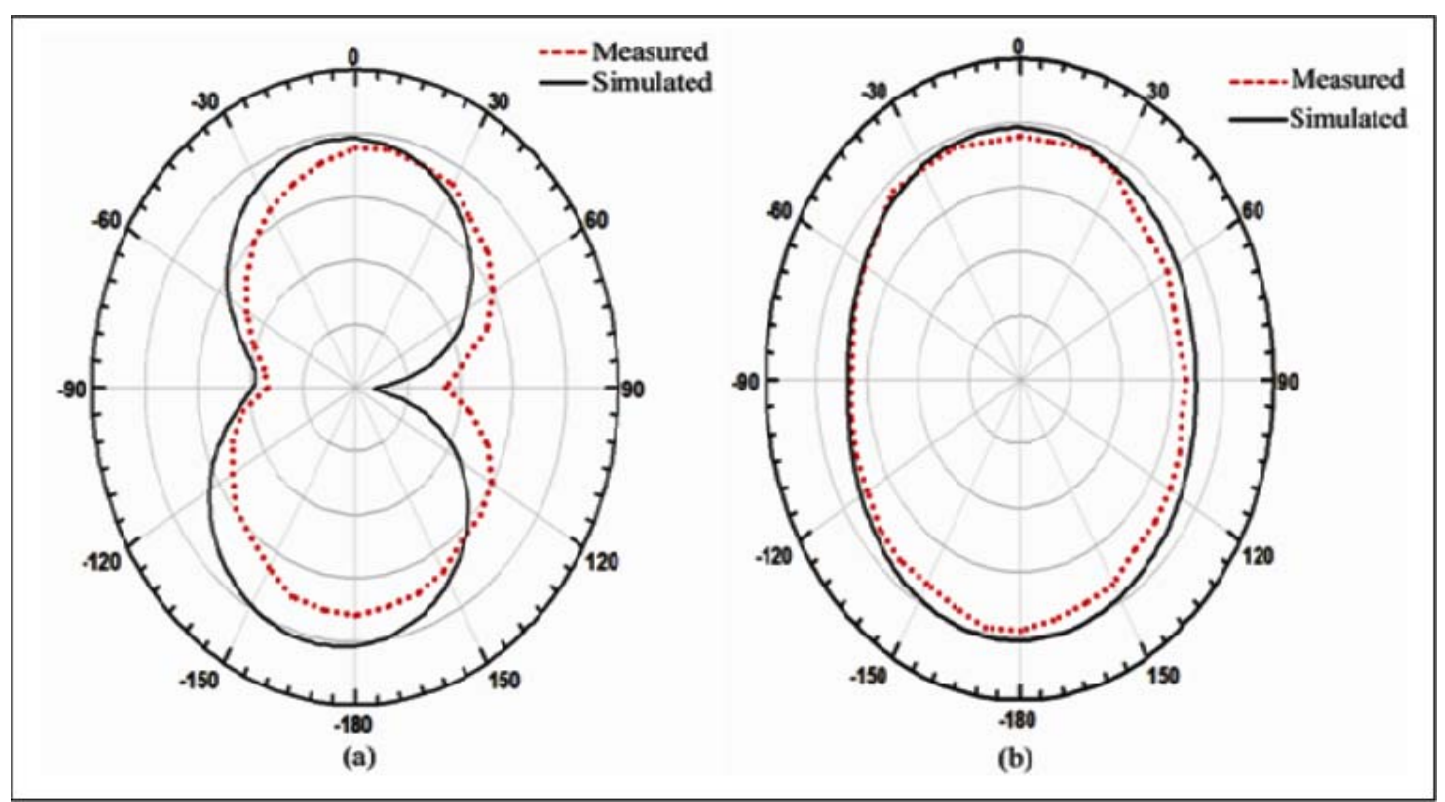

Fig. 7. Comparison of simulated and measured radiation pattern of proposed antenna at $5.20 \mathrm{GHz}$ (a) E-plane and (b) H-plane 


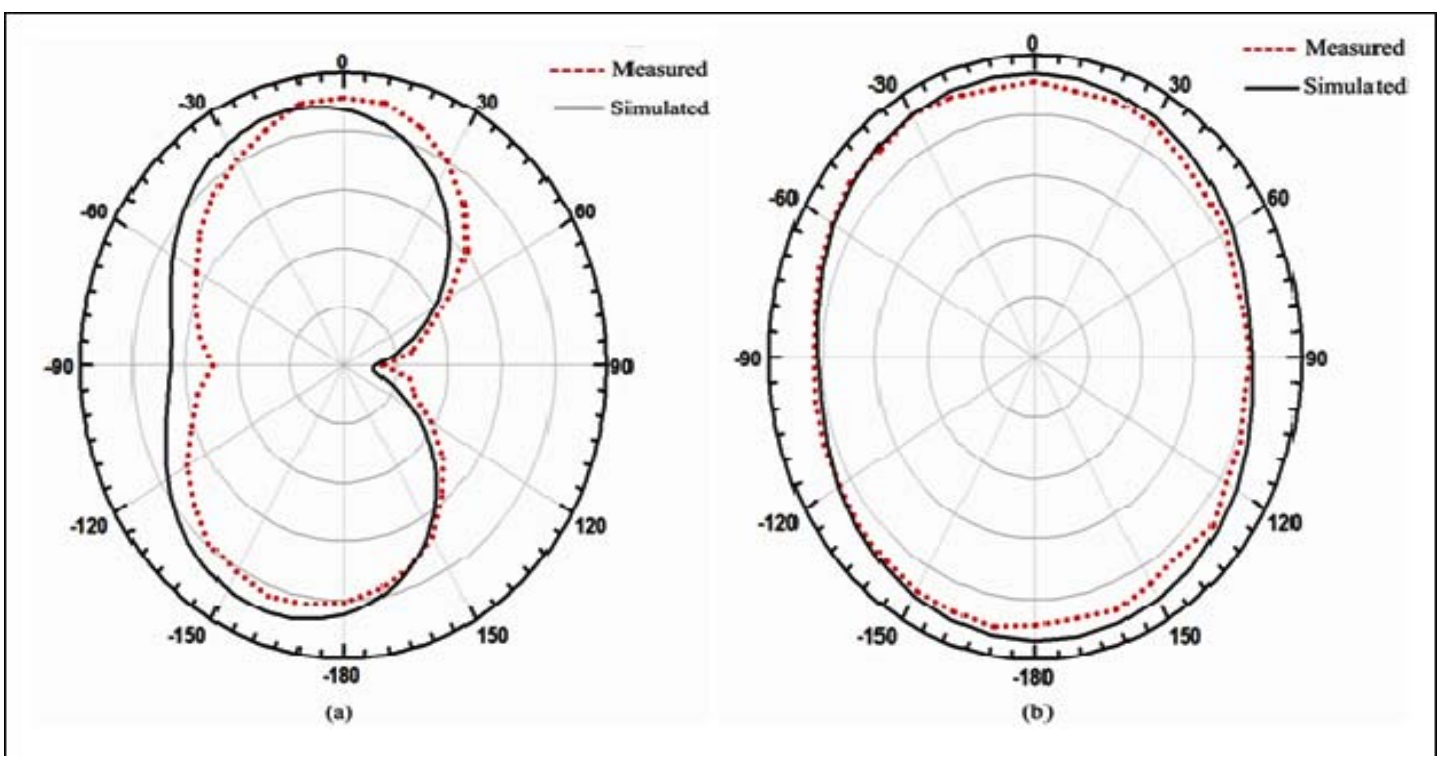

Fig. 8. Comparison of simulated and measured radiation pattern of proposed antenna at $6.54 \mathrm{GHz}$ (a) E-plane and (b) H-plane

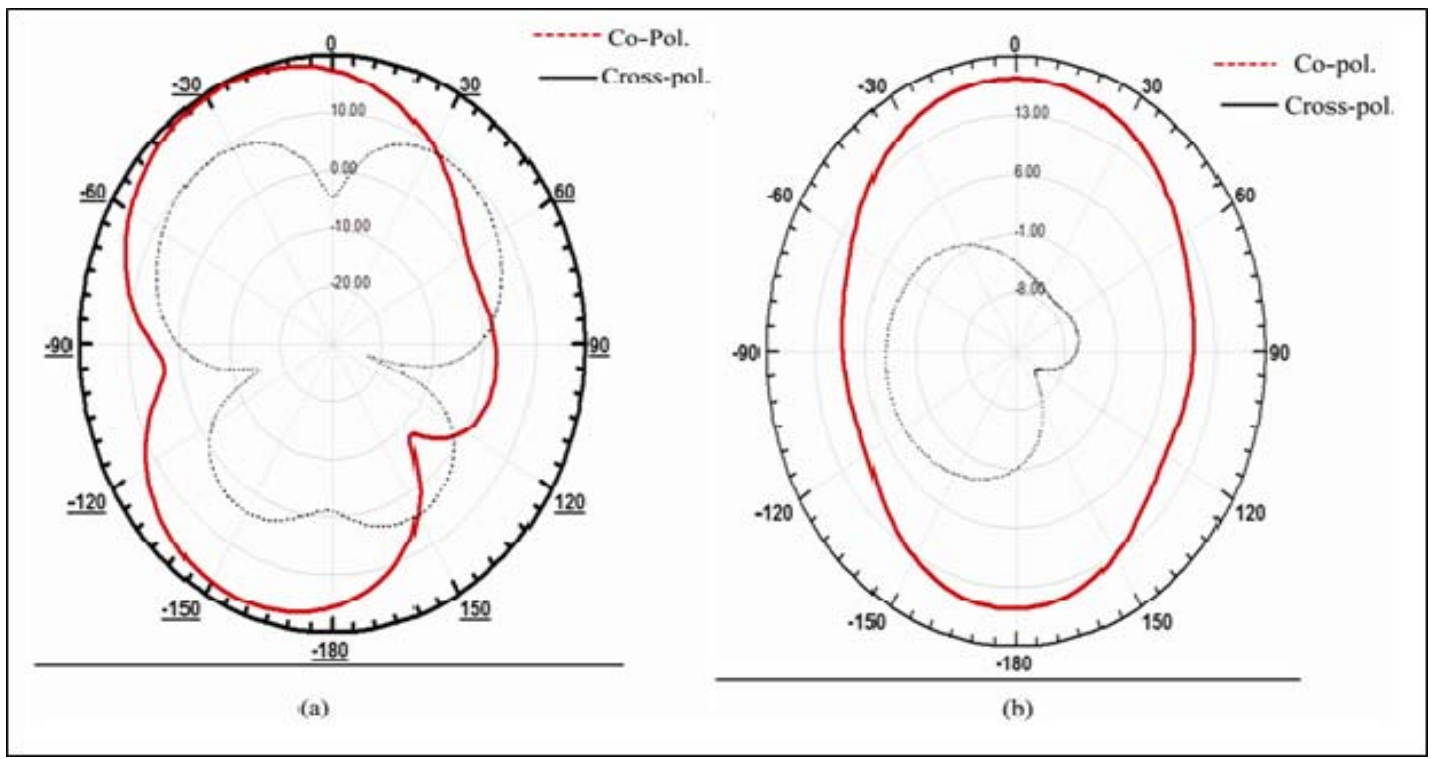

Fig. 9. Simulated radiation pattern of proposed antenna at $7.9 \mathrm{GHz}$ (a) E-plane and (b) H-plane

Figure 10 shows the antenna gain of the proposed antenna at different frequency ranges. The gain at 5.20 $\mathrm{GHz}, 6.54 \mathrm{GHz}$ and $7.9 \mathrm{GHz}$ frequencies are obtained corresponding to $1.55 \mathrm{dBi}, 2.30 \mathrm{dBi}$ and $2.28 \mathrm{dBi}$, respectively. The percentage radiation efficiency of the antenna is shown in Fig. 11. From the plot it is clear that more than $85 \%$ of efficiency has been achieved for proposed antenna. 


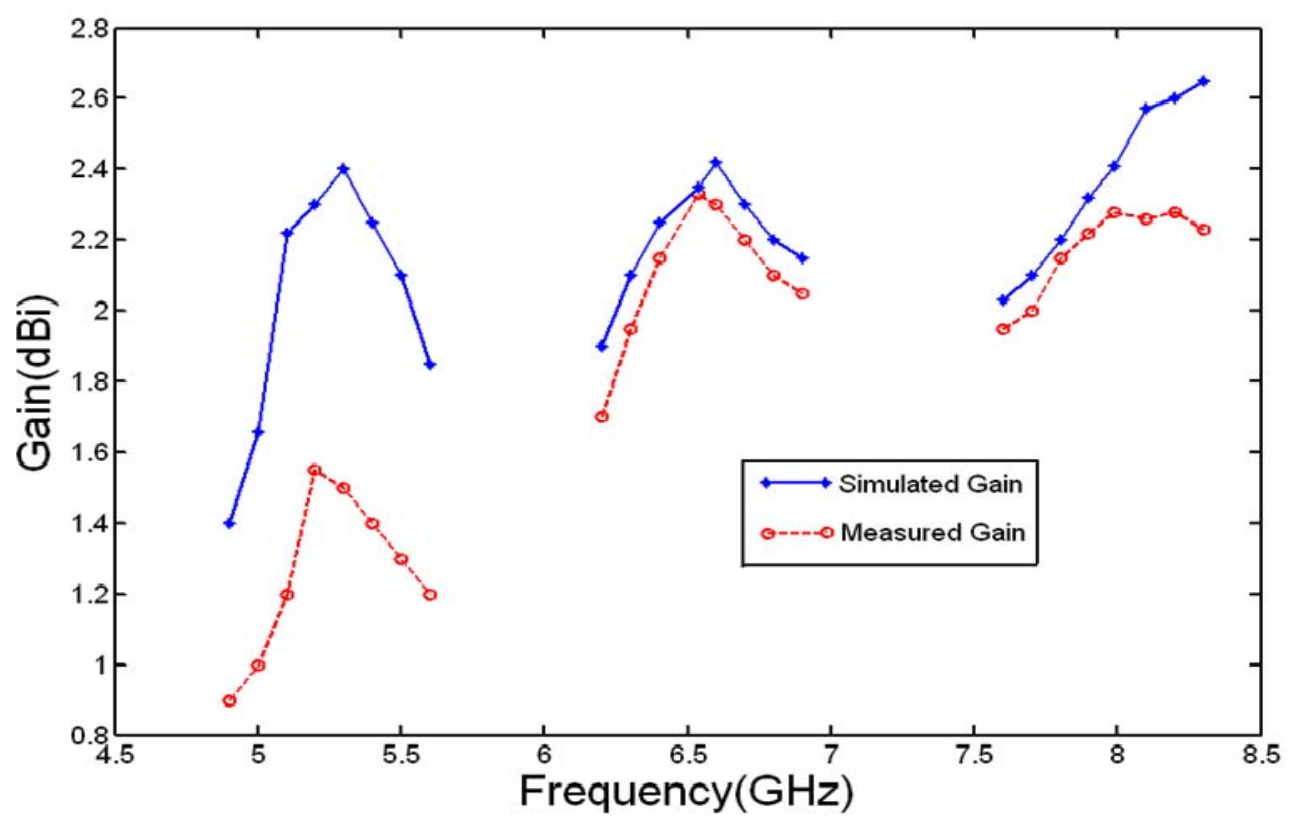

Fig. 10. Measured and simulated gain (dBi) of proposed antenna

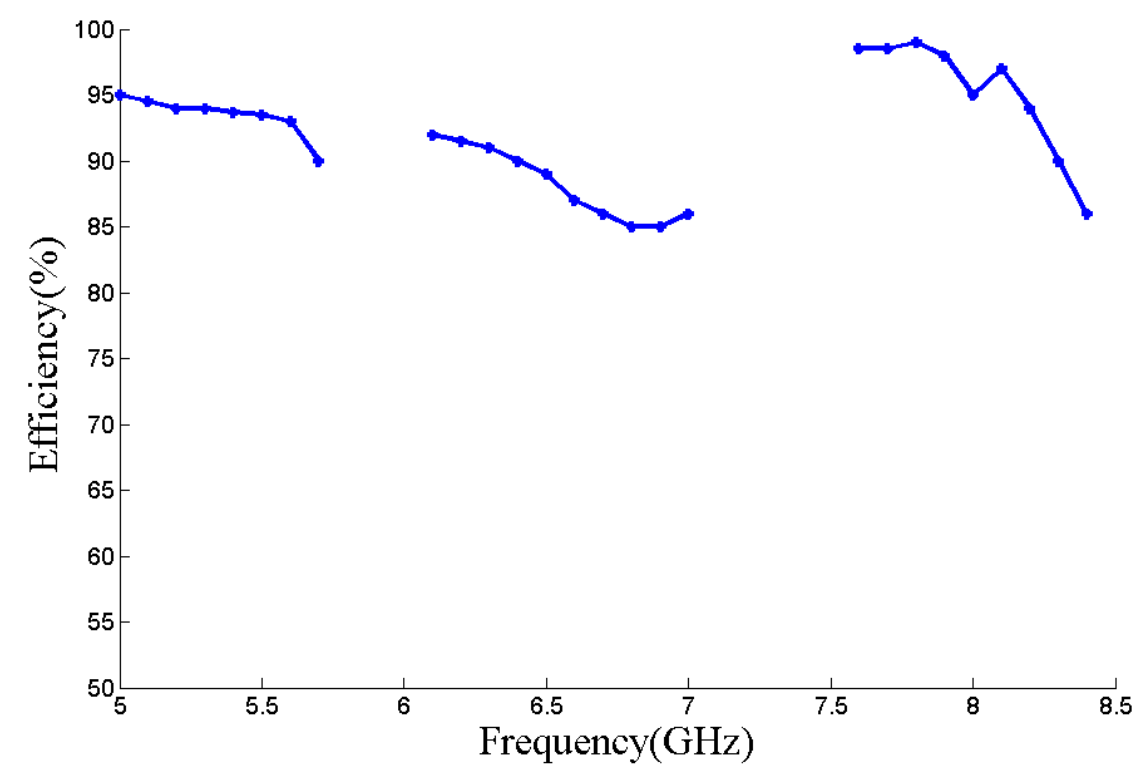

Fig. 11. Variation of simulated efficiency against frequency of proposed antenna

The performance comparison of proposed antenna with some other single band and multiband antenna is shown in Table I. It is found that the proposed microstrip feed antenna has wide-bandwidth and compact in size than earlier design, which covering WLAN, WiMAX and ITU bands in wireless communication. 
TABLE I

Comparison of Proposed Antenna with Some Reference Works

\begin{tabular}{|l|l|l|}
\hline Antenna & Overall dimension $\left.\mathbf{( m m}^{3}\right)$ & Bandwidth (GHz) \\
& & \\
\hline Proposed antenna & $12 \times 16 \times 1.6$ & $4.66(3.68-8.34)$ \\
& & \\
\hline$[3]$ & $29 \times 30 \times 1.6$ & $2.94(4.53-7.47)$ \\
\hline$[12]$ & $38 \times 25 \times 1.6$ & $3.6(2.4-6)$ \\
\hline$[9]$ & $60($ radius $) \times 1.5$ & $1.71(5.45-7.16)$ \\
\hline$[11]$ & $20 \times 13 \times 0.635$ & $0.28(2.4-2.68)$ \\
& & $3.1(3.85-6.95)$ \\
\hline$[8]$ & $22 \times 25 \times 1.6$ & $0.1(2.38-2.49)$ \\
& & $2.94(3.4-6.34)$ \\
\hline$[10]$ & $40 \times 45 \times 1.58$ & $3.10(3-6.10)$ \\
\hline$[13]$ & - & $3.71(3.49-7.20)$ \\
\hline$[14]$ & $18 \times 28 \times 1.6$ & $0.22(3.49-7.2)$ \\
& & $0.47(3.36-3.83)$ \\
& & $1.46(4.83-6.29)$ \\
\hline
\end{tabular}

\section{CONCLUSION}

In this paper, a single layer compact microstrip feed wideband patch antenna has been proposed. The aim of this work is to design not only a wide bandwidth characteristic but also reduced the effective area of the patch size, while having multiband operations. The measured impedance bandwidth has been enhanced by three nearby resonant modes are merged together. The measured bandwidth has covered a range of frequency from $3.68 \mathrm{GHz}$ to $8.34 \mathrm{GHz}$ (BW: $4.66 \mathrm{GHz}$ ) and the effective reduction of the patch size is $50.2 \%$. The measured VSWR is found to be below 2 over the whole operating band and achieved acceptable gain of the resonant frequencies thus it can be treated as within acceptable limit for practical purposes. From the covered bandwidth it can be justified that the proposed antenna is suitable for application of WLAN, WiMAX and ITU in wireless communication.

\section{REFERENCES}

[1] G. Kumar, and K. P. Ray, Broadband Microstrip Antenna, 2nd ed., Artech House, London, 2003.

[2] R. Rajkumar, and K. U. Kiran, "Compact metamaterial multiband antenna for WLAN/WiMAX/ITU band applications," International Journal of Electronics and Communications., vol. 70, pp. 599-604, May. 2016.

[3] Kamakshi, J. A. Ansari, A. Singh, and M. Aneesh, "Desktop shaped broadband microstrip patch antennas for wireless communications," Progress In Electromagnetics Research Letters, vol. 50, pp. 13-18, 2014.

[4] J. Ge, and L. Jin, "A compact multiband bow-tie dipole slot antenna for WLAN and WiMAX applications," Progress In Electromagnetics Research Letters, vol. 56, pp. 17-23, 2015.

[5] C. Y. Pan, J. Y. Jan, and L. C. Wang, "Compact and broadband microstrip line-fed modified rhombus slot antenna," Radioengineeriong, vol. 22, pp. 694-699, Sept. 2013.

[6] T. Sedghi, S. Shafei, A. Kalami, and T. Aribi, "Small monopole antenna for IEEE 802.11a and X-bands applications using modified CBP structure," Wireless Personal Communication, vol. 80, pp. 859-865, Jan. 2015.

[7] Md. R. Ahsan, Md. T. Islam, and Md. H. Ullah, "A new low profile inverted A-shaped patch antenna for multi-band operations," Wireless Personal Communications, vol. 81, pp. 519-529, Mar. 2015.

[8] C. M. Wu, J. W. Syu, and W. C. Liu, "Dual band slotted patch antenna with defective ground for WLAN/WiMAX applications," Progress In Electromagnetics Research Letters, vol. 53, pp. 1-6, 2015.

[9] Y. Ahang, J. Liu, Z. Liang, and Y. Long, “A wide bandwidth monopole patch antenna with dual ring couplers," International Journal of Antennas and Propagation., vol. 2014, pp. 1-6, Jan. 2014.

[10] C. K. Ghosh, S. Mondal, and S. K. Parui, "Compact multiband microstrip antenna using complementary slots on the ground plane," Microwave and Optical Technology Letters, vol. 58, pp. 47-51, Nov. 2015.

[11] S. C. Basaran, and K. Sertel, "Dual wideband cpw-fed monopole antenna with split ring resonators," Microwave and Optical Technology Letters., vol. 55, pp. 2088-2092, Jan. 2013.

[12] A. K. Gautam, A. Bisht, and B. K. Kanaujia, "A wide band antenna with defected ground plane for WLAN/WiMAX applications," International Journal of Electronics and Communications (AEU), vol. 70, pp. 354-358, Mar. 2016.

[13] R. K. Choudhury, R. Kumar, and K. V. Srivastava, "Wideband ring dielectric resonator antenna with annular shaped microstrip feed," IEEE Antenna and Wireless Propagation Letters, vol. 12, pp. 595-598, Apr. 2013.

[14] H. Chan, Y. Z. Yin, and J. J. Wu, “Compact tri-band meandered ring monopole antenna with two embedded strips for WLAN/WiMAX applications," Progress In Electromagnetics Research Letters, vol. 45, pp. 63-67, 2014. 


\section{AUTHOR PROFILE}

Biplab Bag is received his M.Tech degree from West Bengal University of Technology, West Bengal. He is currently working as an Assistant Professor at the Department of Electronics and Instrumentation Engineering, Murshidabad College of Engineering Technology. His research interests include Microstrip Antenna Design for wireless communication systems and Image Processing.

Dr. Partha Pratim Sarkar was felicitated with a Ph. D in engineering from Jadavpur University in the year 2002. He has obtained his M.E from Jadavpur University in the year 1994. He earned his B.E degree in Electronics and Telecommunication Engineering from Bengal Engineering College in the year 1991. He is presently working in the rank of Professor at the Dept. of Engineering and Technological Studies, University of Kalyani. His area of research includes, Microstrip Antenna, Microstrip Filter, Frequency Selective Surfaces, and Artificial Neural Network. He has contributed to numerous research articles in various journals and conference of repute. He is also a life Fellow of IETE and IE (India). 